\title{
BARRIERS, TRENDS AND RESEARCH AGENDA TO EMPLOY EMPIRICALLY VALUE Perspectives
}

Fernando Henrique Lermen ( UNESPAR.

Sânia da Costa Fernandes (saniafernandes@usp.br) - Universidade Presbiteriana Mackenzie/ Universidade de São Paulo, Mackenzie/USP.

Marcia Elisa Echeveste (echeveste.mar@gmail.com) - Universidade Federal do Rio Grande do Sul, UFRGS.

Henrique Rozenfeld (ㅁoz@usp.br) - Universidade de São Paulo, USP.

José Luis Duarte Ribeiro (ribeiro@ producao.ufrgs.br) - Universidade Federal do Rio Grande do Sul, UFRGS.

\section{AbSTRACT}

Value is a concept widely used in the literature and has been deployed in several perspectives. However, those perspectives are not well clarified to be adopted systematically, and the trends and the interrelation between them should be elucidated. This study aims to propose a theoretical framework for value perspectives, and to identify barriers and a research agenda related to them. Based on a systematic literature review combined with community structure and PageRank analysis, we conducted a bibliometric and content analysis of influential documents related to the value perspectives. We determined that value creation and perceived value are well-established perspectives and that there are new perspectives, namely value trade-off and value ecosystem. This study proposes a framework to support the understanding and implementation of value perspectives, identifies the barriers to empirically employing the perspectives, and presents a related research agenda to advance this field.

Keywords: Value perspective; Offering's development; Management; Strategic; Review. 


\section{INTRODUCTION}

The concept of value has been discussed in literature through different perspectives, in which the most commonly employed are value creation (Amit \& Zott, 2001), value proposition (Johnson et al., 2008), perceived value (Sweeney \& Soutar, 2001), value capture (Chesbrough \& Rosenbloom, 2002), value delivery (Lindgreen \& Wynstra, 2005), and uncaptured value (Graham et al., 2006).

In empirical terms, value perspectives have been associated with a series of outcomes, such as interactions in marketing in services (Leroi-Werelds et al., 2017), consumer perception (Mcdougall \& Levesque, 2000), sustainable offerings (Lermen et al., 2020), and business model innovation (Meier et al., 2011). Other studies involving methodological discussions have applied value perspectives empirically (Sweeney \& Soutar, 2001). Those studies emphasize the richness of the concept and its impact on academic research in the field of wide management.

However, the literature offers a striking variety of interpretations and empirical means to value investigations. Some authors argue that value can vary considerably, "depending on the source/level of analysis that produces the value" (Lepak et al., 2017, p. 183). Others suggest that it is determined by "perceived power relationships between economic actors" (Bowman \& Ambrosini, 2000).

In this context, the value perspectives should be studied to be adopted systemically, since the contribution of each perspective is not clear yet. There is a lack of shared understanding about the value perspectives employed, which hinders both their analytical clarity in theoretical studies and their predictive power in empirical studies. This seems to be an appropriate opportunity to clarify the trends and relationships between existing value perspectives and the gaps to apply them in different fields.

This paper presents an overview of empirical studies on value perspectives to identify the consolidated perspectives in literature. This study aims to propose a theoretical framework for value perspectives, and to identify barriers and a research agenda related to them.

The contribution of this study is to shed light on how the value perspectives interrelated to each other through a framework combined with a stakeholders' map, and to present the trends, barriers and a research agenda that can facilitate the positioning and development of future studies. 


\section{METHODOLOGY}

The systematic literature review (SLR) method is employed to manage the knowledge available on a specific theme and allow researchers to evaluate the state of the already available evidence (Adams et al., 2017). This study followed the SLR's steps suggested by Tranfield et al. (2003) The complete method of this study was structured in four stages adapted from Agostini \& Nosella (2019): i) data collection, ii) grouping the studies by community, iii) selection of the most influential studies, and iv) content analysis.

\subsection{Data Collection}

The database chosen in this study was the Web of Science, as it offers more detailed citation analysis than other databases and is extensively used by the scientific community (Hu et al., 2020). Moreover, this database offers access to the main journals in the fields of business, management, strategy, marketing, service management and product development (Chapman \& Ellinger, 2019), covering the value perspectives examined in this investigation.

To identify empirical studies on value perspectives, we have used a single search string focusing on empirical studies in October 2020: (("Value Creation" OR "Value Proposition" OR "Perceived value" OR "Value Capture" OR "Value Delivery" OR "Uncaptured value") AND (Empirical OR "Case study" OR Survey)). A study is considered empirical when it seeks to evaluate the functioning of a phenomenon in an applied manner (Powell \& Butterfield, 1994).

For selecting the papers to compose the sample, we employed the Preferred Reporting Items for Systematic Reviews and Meta-Analyses proposed by Moher et al. (2009). We initially found 5,880 documents, and then excluded 1,116 of them, including reviews, editorials, books, book chapters and events. As to the remaining 4,764 documents, only articles with at least 10 citations (tabulated by the Web of Science) were read. The selection of studies with at least 10 citations was the criterion used to identify the relationships between the documents' authors, references, and citations. In the final sample, we analyzed 325 papers from relevant journals for the value perspectives studied. The 325 documents were exported to the reference manager Mendeley ${ }^{\circledR}$ through the BibTeX extension. For the analysis of the citations and cocitations, the processes to modify the data were performed by using the BibExcel ${ }^{\circledR}$ software.

\subsection{Grouping the studies by communities}

The community structure detection algorithm first appeared in the seminal study by Newman (2004), based on the study by Newman \& Girvan (2004). Both studies dealt with the programming and application of the detection algorithm. In community structures, the vertices 
in networks are found to cluster in tightly knit communities with a high density of withincommunity edges and a lower density of between-community edges (Huang et al., 2021).

The groups are divided according to the functioning of a dendrogram, separating the papers with similarities between the edges in a co-citation process. In this study, we used the Gephi ${ }^{\circledR}$ 0.9.2 software to separate the communities through the Modularity Class partition. Then, a randomization of the articles was done, as it produces a better decomposition using the edge weights. In addition, regarding the resolution, we chose to use 0.9 to generate a few communities that can be related with the six value perspectives studied, thus resulting in four different communities. The following section presents the methodology used to prioritize the most influential studies in the sample.

\subsection{Selection of the most influential studies - PageRank analysis}

PageRank analysis is a method of measuring the prestige of a paper (Brin and Page, 1998; Makkar \& Kumar, 2021), which increases as other papers with a high number of citations cite the article in question. Although citations and prestige are sometimes correlated, a higher number of citations may not necessarily indicate high prestige. Hence, PageRank is used to calculate the influence of research papers, as shown by Equation 1:

$$
P R(A)=\frac{(1-d)}{N}+d\left(\frac{P R\left(T_{1}\right)}{C\left(T_{1}\right)}+\cdots+\frac{P R\left(T_{n}\right)}{C\left(T_{n}\right)}\right)
$$

where $\mathrm{A}$ is a paper cited by other papers $\mathrm{T} 1, \ldots, \mathrm{Tn} . \mathrm{C}(\mathrm{Tn})$ are the citations of paper $\mathrm{Tn}$; $\mathrm{PR}(\mathrm{Tn})$ is its PageRank of paper Tn; and $\mathrm{d}$ is an adjustment factor whose value in the original Google algorithm is 0.85 , based on the information that an individual browsing the web follows approximately six hyperlinks before leaving. $\mathrm{N}$ is the size of the network.

This indicator suggests that the probability of citing any one of those papers by cross reference in the citation network is between 0 and 1 . However, to reduce the 325-paper sample, and based on the four communities, we used PageRank to identify the 15 most influential studies by community, totaling 60 studies whose content was to be analyzed. To apply a PageRank analysis (Equation 1), the Gephi ${ }^{\circledR} 0.9 .2$ software was used, through an undirected study with a 0.85 probability and a 0.001 stopping criterion.

\subsection{Content analysis}

The content analysis followed the steps suggested by Elo \& Kyngäs (2008): open coding, categorization, and abstraction. We sought to identify relevant information by a deductive process during the codification from the sample. That information was divided into two parts (categories): (i) bibliometric data and (ii) content analysis of the empirical studies. Finally, the abstraction step supported the discussions between the sampled authors for each community. 
To interpret the highest ranked papers in the sample (categorization), we analyzed the information set out on a flipchart, with the following variables: PageRank number; author (year); paper's title; journal; stakeholders; application context of the study; whether it falls within the six value perspectives; the value definition used; related types of value; dominant areas of knowledge; barriers; and trends. Besides, we identified some barriers in the empirical development of the values, through which we develop a research agenda. We also developed a theoretical value framework with the consolidated value perspectives.

\section{RESULTS AND DISCUSSION}

The application of the method for creating communities, through the Modularity Class applied in the Gephi ${ }^{\circledR}$ 0.9.2 software (section 2.2), resulted in four different communities, as shown in Table 1.

TABLE 1 - Modularity Class for the creation of communities from the studied sample

\begin{tabular}{l|c|c}
\hline Community & Quantity (\%) & Sample's studies \\
\hline 0 & 40.61 & 132 \\
1 & 30.77 & 100 \\
2 & 13.31 & 40 \\
3 & 16.31 & 53 \\
\hline Total & 100.00 & 325 \\
\hline
\end{tabular}

Figure 1 elucidates the co-citation network of the articles in the sample, constituting a complex network of studies and their relationships. It is based on the four previously mentioned communities, which are presented in blue, green, pink, and red.

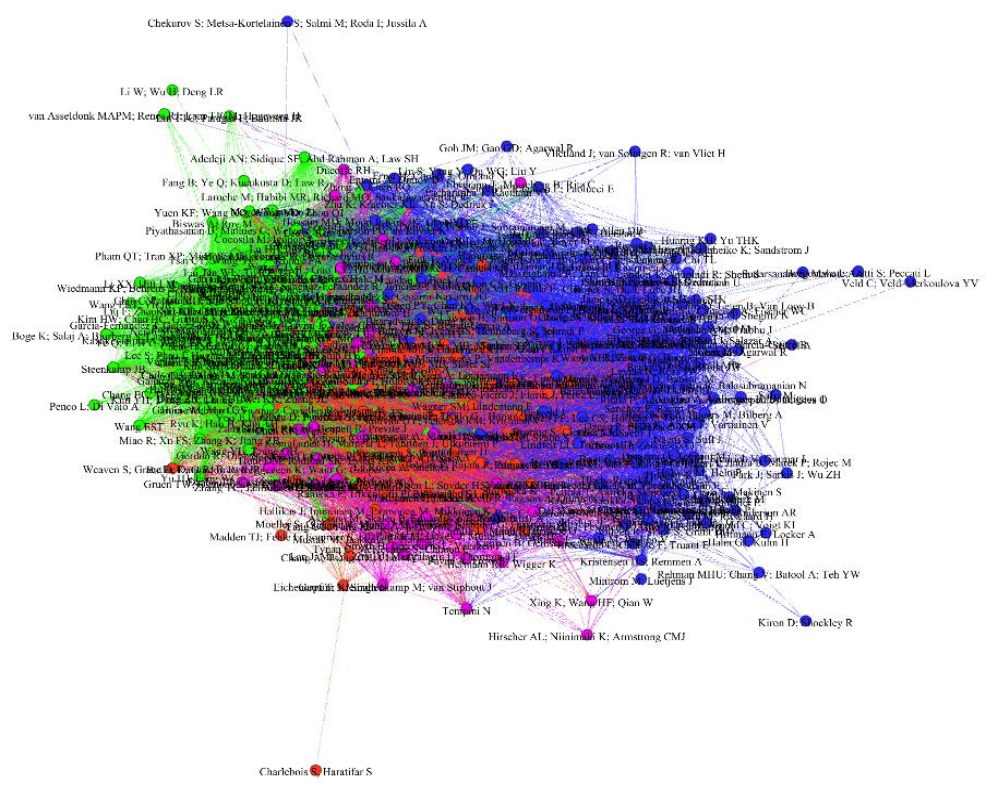

FIGURE 1 - Co-citation network of the value perspective studies

Note: Community 0 is blue, 1 green, 2 pink, 3 red.

As the 325-study sample is considered large, in the following stage, it was necessary to introduce a new filter representing the quality of the papers. It was considered the 15 most 
influential documents for each community, according to PageRank Analysis. The communities were named after the incidence of citations on the value perspectives previously identified in this SLR. They are Community 0 (Value Creation), Community 1 (Perceived Value), Community 2 (Value Trade-off), and Community 3 (Value Ecosystem).

\subsection{Framework of Value Perspectives}

Value creation and perceived value are well-established perspectives in literature. Additionally, to the other commonly employed value perspectives (i.e., value proposition, value capture, value delivery, and uncaptured value), there are new well-established perspectives that emerge from the communities. They are named value trade-off and value ecosystem.

Figure 2 presents the theoretical framework that structures the key information of the value perspectives that emerge from the communities.

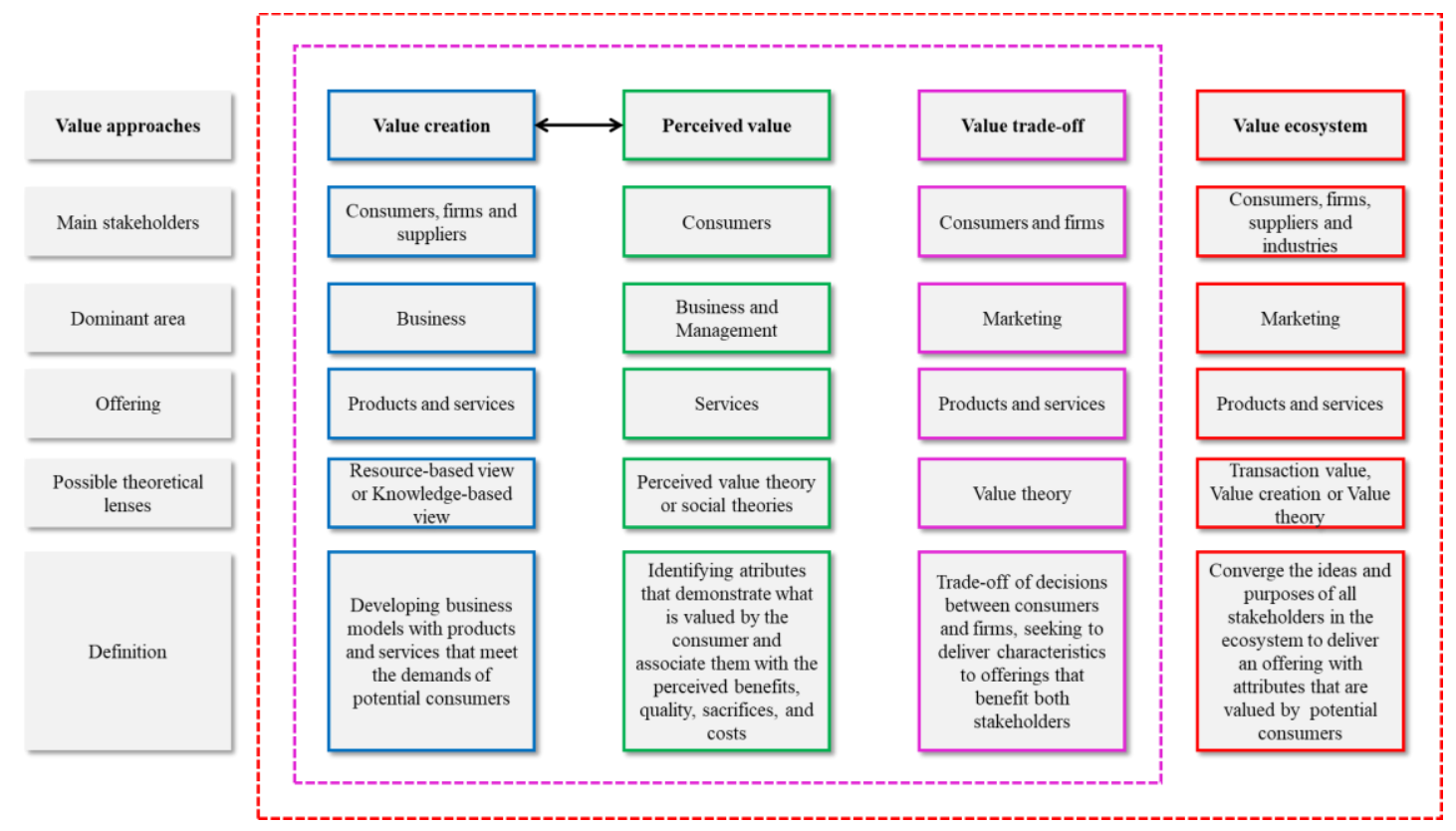

FIGURE 2 - Theoretical framework for value perspectives

The theoretical framework (Figure 2) can support researchers and practitioners on the implementation of value perspectives, improving the development of innovative offerings (products and services) that meet the value demands of consumers and other stakeholders. The perceived value depends on the analysis of the value created; thus, they are interrelated. The value trade-off perspective contemplates the balance between the value perceived by the client and the value created by the firm. Finally, the value ecosystem perspective converges the ideas from all stakeholders and contemplates the other consolidated perspectives. 
To better understand the stakeholders involved with all value perspectives, we propose a stakeholders' map that clarifies how the value perspectives are positioned between them (Figure 3).

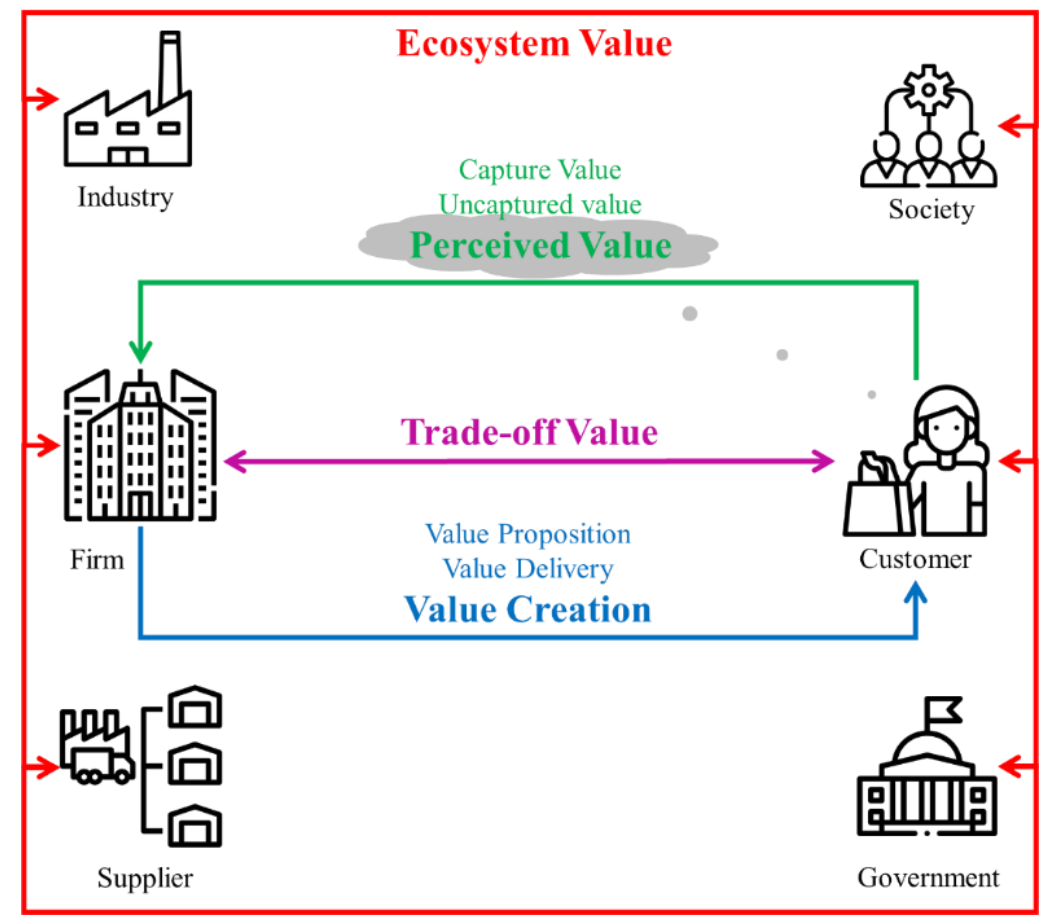

FIGURE 3 - Stakeholders' map positioning the different value perspectives

Some of the perspectives most mentioned in the literature do not appear in the communities because they are already connected to the consolidated perspectives (studied communities). The value proposition perspective is directly connected with value creation, being focused on business model innovation. Value delivery, a firm-to-consumer perspective that seeks to deliver offerings consisting of products and services that meet consumers' needs and desires, is connected to the value creation.

In turn, the perspectives from consumer to firm are connected to the perceived value: the value capture is the value that is captured through an exchange with the consumer and through what is reported to be important; and, the uncaptured value, known as value missed or destroyed (Bocken et al., 2013), occurs when the company is unable to identify what the consumer actually needs.

With regards to the consolidated perspectives presented through the communities, we should highlight the value creation, as its direction is from the firm to consumer, with firms seeking to create offerings that may interest potential consumers. Another consolidated perspective is perceived value, which occurs through the consumer's perception of the product/service, evaluating the attributes that influence their decision, which are inherent to the dimensions of 
visual appreciation, expected-use experience, benefits, quality, sacrifices, and costs. As another community, value trade-off emerges to achieve a win-win proposition for consumer and firm (both are important when identifying what value is). Finally, value ecosystem is concerned with understanding value to all stakeholders in the ecosystem, represented in Figure 3 as consumers, firms, government, industries, suppliers, and society.

\subsection{Barriers to employ Value Perspectives empirically}

One of the main barriers identified in the empirical studies in relation to Community 0 (Value Creation) is the difficulty to apply this perspective and related theories, in which, if incorrectly implemented, do not fill the customer needs by the offerings (Lawson et al., 2012; Martelo-Landroguez \& Cegarra-Navarro, 2014). In addition, the lack of collaboration between all stakeholders, mentioned by Saraf et al. (2007) and Chen et al. (2017) is a barrier for the development of innovative offerings in the ideation phase. The difficulty to identify consumers' value needs and benefits was also recognized as a barrier (Zott \& Amit, 2010; Lindič \& da Silva, 2011; Fink et al., 2017). Finally, with regards to this community, we should highlight the lack of value measurement methods in the initial phases of development of the offerings.

For Community 1 (Perceived value), difficulties were mentioned with regards the implementation of value perspective in developing countries (Wang et al., 2018) and in products and services during the process to understand consumers perception (Hsu \& Lin, 2016). In addition, regarding the consumer perception, there are barriers to establish consumer loyalty (Chen \& Hu, 2010) and to discern consumers during the choice process ( $\mathrm{Lu} \&$ Lin, 2012). Another relevant barrier was the difficulty to identify the attributes and characteristics of consumers' perceived value (Prebensen et al., 2012).

As Community 2 (Value trade-off) focuses on the relations between firms and consumers, a significant barrier was the difficulty to standardize offerings and estimate stakeholders' willingness to pay (Yazdanparast et al., 2010; Song et al., 2016). The lack of consumers' adherence to consumer satisfaction surveys has been reported by several authors as a fundamental barrier (for instance, Johnson, 2007; Siu et al., 2013; Chen \& Wang, 2016; Morosan \& DeFranco, 2016). The same authors also mention a lack of empirical studies dealing with the trade-off between firms and consumers, evidence of which was identified in some articles in the sample.

Finally, the authors of Community 3 (Value ecosystem) highlight the difficulty to enlist the active participation of the ecosystem's stakeholders (Berghman et al., 2012). They also 
mention the difficulty to measure stakeholders demands, in particular, what is valued by consumers (Singh \& Koshy, 2011), as well as the lack of a sequential model that presents the best practices to identify what is valued by the ecosystem (Blocker et al., 2011; Smith et al., 2012).

\subsection{Research Agenda for Future Studies}

Considering the discussion in the previous section, Table 2 presents guiding questions to support scholars, practitioners, managers, and decision makers in empirical applications of the consolidated value perspective.

TABLE 2 - Research agenda for future research

\begin{tabular}{l|l}
\hline Community/Perspective & Research agenda \\
$\begin{array}{l}\text { Community 0 } \\
\text { Value creation }\end{array}$ & $\begin{array}{l}\text { i) What are the attributes prioritized by consumers during the purchasing process? } \\
\text { ii) What are the value measuring methods applied? } \\
\text { iii) How to relate universities and firms to create value in patents and offerings? } \\
\text { iv) How to evaluate stakeholders' relations in the value creation process? }\end{array}$ \\
\hline $\begin{array}{l}\text { Community 1 } \\
\text { Perceived value }\end{array}$ & $\begin{array}{l}\text { i) How to identify perceived value attributes based on the consumer's profile? } \\
\text { iii) How to define mediating and moderating variables in new offerings? }\end{array}$ \\
& $\begin{array}{l}\text { iv) What would be the attributes to be tested by potential consumers in empirical } \\
\text { studies on the perceived value perspective? }\end{array}$ \\
\hline \multirow{3}{*}{ Vommunity 2} & $\begin{array}{l}\text { i) How to create an innovative business through value perspective? } \\
\text { ii) What are the best practices to manage the relation between firm and consumer? } \\
\text { iii) How to measure what value is for both stakeholders in the chain? }\end{array}$ \\
& iv) What are the measuring methods employed by the firm and by the consumer? \\
\hline Value ecosystem & $\begin{array}{l}\text { i) How to evaluate what is valued by different stakeholders? } \\
\text { ii) What are the best ways to identify what is valued by stakeholders? }\end{array}$ \\
& $\begin{array}{l}\text { iii) What practices can be used to bring together the ecosystem's stakeholders? } \\
\text { iv) How to combine the value ecosystem perspective with an innovative ecosystem? }\end{array}$ \\
\hline
\end{tabular}

Considering the questions in Table 2, researchers can carry out empirical and theoretical studies with the purpose of positioning and implementing the value perspectives.

\section{CONCLUSIONS}

This study aimed to propose a theoretical framework for value perspectives, and to identify barriers, trends and a research agenda related to them. Through a systematic literature review, we identified and grouped by communities the most influential documents (PageRank Analysis). Based on the 60 papers in the final sample, the value creation and perceived value are consolidated value perspectives in literature, in which the first is related to the business field and the latter in service management. Value trade-off and value ecosystem perspectives were also identified as Communities; they are positioned in the marketing field, focusing, respectively, on the relationship between firm and consumer and the relationships between all stakeholders. 
This study contributes to theory by advancing the discussion about the consolidated value perspectives in literature through the proposition of a framework, which presents the analysis of the stakeholders, dominant area, related offerings, and possible theoretical lenses. Descriptions for each value perspective was also proposed to support an analytical clarity and shared understanding about them. The research agenda, based on the barriers and trends, can support the development of practical studies to advance in this field.

Regarding the practical implications, this study can aid practitioners in building awareness of the consolidated value perspectives involved in the development of innovative offerings (products and services). Furthermore, the framework for value perspectives can be used as a basis for reasoning to facilitate the effective implementation of the value perspectives.

Although this study is a systematic review with a relevant initial sample ( $\mathrm{n}=325$ papers), the fact that it is restricted to the 15 most relevant papers from each community (60 papers as final sample) according to PageRank Analysis may be a limitation. However, this was necessary to converge to definitions that are effectively recognized, considering the large number of citations in the top-15 selected articles. For future research, we suggest the development of empirical studies following the research agenda presented in Section 3.3, especially studies concerning value trade-off and value ecosystem, which are perspectives that still need further studies.

\section{ACKNOWLEDGEMENTS}

The authors would like to acknowledge the financial support of CAPES - Coordination of Improvement of Higher-Level Personnel, $\mathrm{CNPq}$ - the Brazilian National Council for Scientific and Technological Development, and FAPESP - São Paulo Research Foundation. Besides, this study was supported by São Paulo Research Foundation (FAPESP) under the processes 2017/27144-3. The opinions, hypotheses and conclusions or recommendations expressed in this material are of responsibility of the authors and do not necessarily reflect the views of FAPESP.

\section{REFERÊNCIAS}

Adams, R. J., Smart, P., \& Huff, A. S. (2017). Shades of grey: guidelines for working with the grey literature in systematic reviews for management and organizational studies. International Journal of Management Reviews, 19(4), 432-454.

Agostini, L., \& Nosella, A. (2019). Inter-organizational relationships involving SMEs: A bibliographic investigation into the state of the art. Long Range Planning, 52(1), 1-31.

Amit, R., \& Zott, C. (2001). Value creation in e-business. Strategic Management Journal, 22(6). 
Berghman, L., Matthyssens, P., \& Vandenbempt, K. (2012). Value innovation, deliberate learning mechanisms and information from supply chain partners. Industrial Marketing Management.

Blocker, C. P., Flint, D. J., Myers, M. B., \& Slater, S. F. (2011). Proactive customer orientation and its role for creating customer value in global markets. Journal of the Academy of Marketing Science, 39(2), 216-233.

Bocken, N., Short, S., Rana, P., \& Evans, S. (2013). A value mapping tool for sustainable business modelling. Corporate Governance, 13(5), 482-497.

Bowman, C., \& Ambrosini, V. (2000). Value creation versus value capture: towards a coherent definition of value in strategy. British Journal of Management, 11(1), 1-15.

Brin, S., \& Page, L. (1998). The anatomy of a large-scale hypertextual Web search engine. Computer Networks and ISDN Systems, 30(1-7), 107-117.

Chapman, K., \& Ellinger, A. E. (2019). An evaluation of Web of Science, Scopus and Google Scholar citations in operations management. The International Journal of Logistics Management.

Chen, C. F., \& Wang, J. P. (2016). Customer participation, value co-creation and customer loyalty-A case of airline online check-in system. Computers in Human Behavior, 62, 346-352.

Chen, P. T., \& Hu, H. H. (2010). The effect of relational benefits on perceived value in relation to customer loyalty: An empirical study in the Australian coffee outlets industry. International Journal of Hospitality Management, 29(3), 405-412.

Chen, P. Y., Chen, K. Y., \& Wu, L. Y. (2017). The impact of trust and commitment on value creation in asymmetric buyer-seller relationships: the mediation effect of specific asset investments. Journal of Business \& Industrial Marketing, 32(3), 457-471.

Chesbrough, H., \& Rosenbloom, R. S. (2002). The role of the business model in capturing value from innovation: evidence from Xerox Corporation's technology spin-off companies. Industrial and Corporate Change, 11(3), 529-555.

Elo, S., \& Kyngäs, H. (2008). The qualitative content analysis process. Journal of Advanced Nursing, 62(1),107115.

Fink, L., Yogev, N., \& Even, A. (2017). Business intelligence and organizational learning: An empirical investigation of value creation processes. Information \& Management, 54(1), 38-56.

Graham, J. R., Harvey, C. R., \& Rajgopal, S. (2006). Value destruction and financial reporting decisions. Financial Analysts Journal, 62(6), 27-39.

Hsu, C. L., \& Lin, J. C. C. (2016). Effect of perceived value and social influences on mobile app stickiness and in-app purchase intention. Technological Forecasting and Social Change, 108.

Hu, G., Wang, L., Ni, R., \& Liu, W. (2020). Which h-index? An exploration within the Web of Science. Scientometrics, 1-9.

Huang, Z., Wu, J., Zhu, W., Wang, Z., Mehrotra, S., \& Zhao, Y. (2021). Visualizing complex networks by leveraging community structures. Physica A: Statistical Mechanics and its Applications, 565, 125506.

Johnson, D. S. (2007). Achieving customer value from electronic channels through identity commitment, calculative commitment, and trust in technology. Journal of Interactive Marketing.

Johnson, M. W., Christensen, C. M., \& Kagermann, H. (2008). Reinventing your business model. Harvard Business Review, 86(12), 50-59.

Lawson, B., Samson, D., \& Roden, S. (2012). Appropriating the value from innovation: inimitability and the effectiveness of isolating mechanisms. $R \& D$ Management, 42(5), 420-434.

Lepak, D. P., Smith, K. G., \& Taylor, M. S. (2007). Value creation and value capture: A multilevel perspective. Academy of Management Review, 32(1), 180-194.

Lermen, F. H., Ribeiro, J. L. D., Echeveste, M. E., Martins, V. L. M., \& Tinoco, M. A. C. (2020). Sustainable offers for drying and storage of grains: Identifying perceived value for Brazilian farmers. Journal of Stored Products Research, 87, 101579. 
Leroi-Werelds, S., Streukens, S., Van Vaerenbergh, Y., \& Grönroos, C. (2017). Does communicating the customer's resource integrating role improve or diminish value proposition effectiveness? Journal of Service Management, 28(4), 618-639.

Lindgreen, A., \& Wynstra, F. (2005). Value in business markets: What do we know? Where are we going?. Industrial Marketing Management, 34(7), 732-748.

Lindič, J., \& Da Silva, C. M. (2011). Value proposition as a catalyst for a customer focused innovation. Management Decision, 49(10), 1694-1708.

Lu, H. P., \& Lin, K. Y. (2012). Factors influencing online auction sellers' intention to pay: an empirical study integrating network externalities with perceived value. Journal of Electronic Commerce Research, 13(3), 238.

Makkar, A., Ghosh, U., Sharma, P. K., \& Javed, A. (2021). A Fuzzy-based approach to Enhance Cyber Defence Security for Next-generation IoT. IEEE Internet of Things Journal. In Press.

Martelo-Landroguez, S., \& Cegarra-Navarro, J. G. (2014). Linking knowledge corridors to customer value through knowledge processes. Journal of Knowledge Management, 18(2).

McDougall, G. H., \& Levesque, T. (2000). Customer satisfaction with services: putting perceived value into the equation. Journal of Services Marketing. 14(5), 392-410.

Meier, H., Völker, O., \& Funke, B. (2011). Industrial product-service systems (IPS 2): Paradigm shift by mutually determined products and services. The International Journal of Advanced Manufacturing Technology, 52(9), 1175-1191.

Moher, D., Liberati, A., Tetzlaff, J., Altman, D. G., \& Prisma Group. (2009). Preferred reporting items for systematic reviews and meta-analyses: the PRISMA statement. PLoS Medicine, 6(7).

Morosan, C., \& DeFranco, A. (2016). Co-creating value in hotels using mobile devices: A conceptual model with empirical validation. International Journal of Hospitality Management.

Newman, M. E. (2004). Fast algorithm for detecting community structure in networks. Physical review E, 69(6), 066133.

Newman, M. E., \& Girvan, M. (2004). Finding and evaluating community structure in networks. Physical review E, 69(2), 026113.

Powell, G. N., \& Butterfield, D. A. (1994). Investigating the "glass ceiling" phenomenon: An empirical study of actual promotions to top management. Academy of Management Journal.

Prebensen, N. K., Woo, E., Chen, J. S., \& Uysal, M. (2013). Motivation and involvement as antecedents of the perceived value of the destination experience. Journal of Travel Research.

Saraf, N., Langdon, C. S., \& Gosain, S. (2007). IS application capabilities and relational value in interfirm partnerships. Information Systems Research, 18(3), 320-339.

Singh, R., \& Koshy, A. (2011). Does salesperson's customer orientation create value in B2B relationships? Empirical evidence from India. Industrial Marketing Management, 40(1), 78-85.

Siu, N. Y. M., Zhang, T. J. F., Dong, P., \& Kwan, H. Y. (2013). New service bonds and customer value in customer relationship management: The case of museum visitors. Tourism Management.

Smith, L., Ng, I., \& Maull, R. (2012). The three value proposition cycles of equipment-based service. Production Planning \& Control, 23(7), 553-570.

Song, H., Cadeaux, J., \& Yu, K. (2016). The effects of service supply on perceived value proposition under different levels of customer involvement. Industrial Marketing Management.

Sweeney, J. C., \& Soutar, G. N. (2001). Consumer perceived value: The development of a multiple item scale. Journal of Retailing, 77(2), 203-220.

Tranfield, D., Denyer, D., \& Smart, P. (2003). Towards a methodology for developing evidence-informed management knowledge by means of systematic review. British Journal of Management, 14(3), $207-222$.

Wang, Y., Hazen, B. T., \& Mollenkopf, D. A. (2018). Consumer value considerations and adoption of remanufactured products in closed-loop supply chains. Industrial Management \& Data Systems, 118(8).

Yazdanparast, A., Manuj, I., \& Swartz, S. M. (2010). Co-creating logistics value: a service-dominant logic perspective. The International Journal of Logistics Management, 21(3), 375-403. 
Zott, C., \& Amit, R. (2010). Business model design: An activity system perspective. Long Range Planning, $43(2-3), 216-226$. 